\title{
22q I I deletion syndrome: a review of the neuropsychiatric features and their neurobiological basis
}

This article was published in the following Dove Press journal:

Neuropsychiatric Disease and Treatment

3 December 2013

Number of times this article has been viewed

\section{Chiara Squarcione \\ Maria Chiara Torti \\ Fabio Di Fabio \\ Massimo Biondi}

Department of Neurology and Psychiatry, Sapienza University of Rome, Rome, Italy
Correspondence: Chiara Squarcione Department of Neurology and Psychiatry, Sapienza University of Rome, Viale dell'Università 30, 00185 Rome, Italy Tel +3906 499l 4539

Email chiarasquarcione@hotmail.com
Abstract: The 22q11.2 deletion syndrome (22q11DS) is caused by an autosomal dominant microdeletion of chromosome 22 at the long arm (q) 11.2 band. The 22q11DS is among the most clinically variable syndromes, with more than 180 features related with the deletion, and is associated with an increased risk of psychiatric disorders, accounting for up to $1 \%-2 \%$ of schizophrenia cases. In recent years, several genes located on chromosome $22 \mathrm{q} 11$ have been linked to schizophrenia, including those encoding catechol-O-methyltransferase and proline dehydrogenase, and the interaction between these and other candidate genes in the deleted region is an important area of research. It has been suggested that haploinsufficiency of some genes within the 22q11.2 region may contribute to the characteristic psychiatric phenotype and cognitive functioning of schizophrenia. Moreover, an extensive literature on neuroimaging shows reductions of the volumes of both gray and white matter, and these findings suggest that this reduction may be predictive of increased risk of prodromal psychotic symptoms in 22q11DS patients. Experimental and standardized cognitive assessments alongside neuroimaging may be important to identify one or more endophenotypes of schizophrenia, as well as a predictive prodrome that can be preventively treated during childhood and adolescence. In this review, we summarize recent data about the 22q11DS, in particular those addressing the neuropsychiatric and cognitive phenotypes associated with the deletion, underlining the recent advances in the studies about the genetic architecture of the syndrome.

Keywords: 22q11 deletion syndrome, microdeletion, neuropsychiatric disorders, cognitive impairments

\section{Introduction}

The $22 \mathrm{q} 11.2$ deletion syndrome (22q11DS) is one of the most common multiple anomaly syndromes, caused by an autosomal dominant microdeletion of chromosome 22 at the long arm (q) 11.2 band, one of the most frequent known interstitial deletions identified in humans. The microdeletion occurs at a population frequency of around 1:4,000 live births, ${ }^{1}$ although published estimates vary from approximately 1:2,000 to $1: 6,000$ live births; $;^{2,3}$ it represents one of the most common known recurrent copy number variants (CNVs).

Common physical manifestations of the disorders include mild dysmorphic facial features, congenital cardiovascular anomalies, palatal defects with velopharyngeal insufficiency, submucous cleft palate and hypernasal speech, thymic hypoplasia with immunodeficiency, hypocalcemia, and a broad spectrum of neuropsychiatric disorders. To date, it is well known that in most cases, 22q11DS is caused by a hemizygous deletion of 3 million base pairs of DNA encompassing approximately 40 known genes, 
while $8 \%$ have smaller nested deletions of 1.5 million base pairs spanning 34 known genes. ${ }^{4,5}$

\section{History of the syndrome}

The first documentation of the syndrome, in that time named velocardiofacial syndrome (VCFS), was in $1978,{ }^{6}$ and it focused exclusively on the clinical importance of a pattern of congenital malformations in 12 patients; there were no data relating to the chromosomal and genetic profile of these patients.

The $22 q 11 D S$ is among the most clinically variable syndromes, with more than 180 features associated with the deletion. Throughout its history, 22q11DS has been called by many names, including not only the already mentioned VCFS $^{7,8}$ or Shprintzen syndrome, but also Sedlačková syndrome, ${ }^{9,10}$ DiGeorge syndrome, ${ }^{11}$ conotruncal anomaly face syndrome, Cayler syndrome, ${ }^{12,13}$ and CATCH 22 (cardiac abnormality, abnormal face, T-cell deficits, cleft palate, and hypocalcemia); ${ }^{14}$ this last eponym was proposed in order to unify the rapidly expanding number of conditions that were found to be caused by the 22q11.2 deletion, but it was rejected ${ }^{15}$ because of the association with Joseph Heller's homonymous black humor novel, representing a no-win situation, something that is obviously inappropriate for the 22 q11DS that can often be treated very effectively.

This diversity of names reflects the variable phenotype that results from 22q11.2 deletions. In fact, the phenotype associated with this microdeletion is highly variable and involves multiple organ systems. ${ }^{5}$ It was widely demonstrated that phenotypic variability can be caused by breakpoint heterogeneity as well as other genetic, environmental, and stochastic factors. Studies have shown that this variability is not only dependent on genotype: to date, no consistent correlations have been detected between deletion extent and phenotype despite the increasing attention on the correlation between CNVs and the susceptibility to cognitive disorders and schizophrenia. ${ }^{16}$ Furthermore, there are many published examples of affected relatives that demonstrate that the clinical presentation can be widely different even within a single family. Studies of monozygotic twins with 22q11.2 deletion have demonstrated that identical deletions do not ensure identical phenotypes. ${ }^{17,18}$ In light of such evidence, it is possible to affirm that genotype alone cannot entirely predict the outcome of 22q11.2 deletions, as for schizophrenia and other complex genetic disorders. ${ }^{19}$

At this time, fluorescence in situ hybridization (FISH) is the diagnostic procedure most commonly used to identify the deletion on the basis of clinical suspicion. This procedure involves the use of DNA probes to determine if a specific region of the genome is present in two copies in a chromosome preparation obtained from peripheral blood, denatured in order to allow the hybridization of a probe specific to the site in question (in this case, the $22 \mathrm{q} 11.2$ region). FISH for a 22 q11.2 deletion is essentially accurate $100 \%$ of the time. ${ }^{3}$

As described above, in addition to the physical features of the $22 \mathrm{q} 11 \mathrm{DS}$, this syndrome is associated with high rates of psychiatric disorder across the lifespan. ${ }^{20}$ In the spectrum of the multiple anomalies related to the syndrome, the behavioral and developmental disorders have aroused much attention from the scientific community since the first report of psychiatric disorders in 1992. ${ }^{21}$ This report coincided with the identification of the deletion from $22 q 11.2$, and this coincidence suddenly drew substantial research interest to identify the gene that resided in the deleted region that would influence psychiatric phenotypes. ${ }^{8,16}$ In recent years, several genes located on chromosome $22 \mathrm{q} 11$ have been linked to schizophrenia, including catechol-O-methyltransferase $(C O M T)^{22-24}$ and proline dehydrogenase (PRODH). ${ }^{25-27}$ Other functional candidate genes from within this region include those encoding $G$ protein, beta polypeptide 1-like (GNB1L), phosphatidylinositol 4-kinase, catalytic, alpha (PIK4CA), and armadillo repeat gene deleted in velocardiofacial syndrome (ARVCF). The deletion is thought to disrupt the expression of multiple genes involved in maturation and development of neurons and neuronal circuits and neurotransmission. In a study by van Beveren et al, ${ }^{28}$ decreased expression of several genes (among which COMT, and genes encoding ubiquitin fusion degradation protein 1-like (UFD1L), PC2 glutamine/Q-rich-associated protein $(P C Q A P)$, and $G N B 1 L$ ) previously linked to schizophrenia has been identified, as well as involvement of signaling pathways relevant to schizophrenia, of which neurotrophin/ tyrosine protein kinase receptors and neuregulin signaling seems to be especially notable. It is important to note that this study was performed by whole-genome gene expression of peripheral blood mononuclear cells of a small sample of patients, and the use of this kind of peripheral cell sampling to investigate brain molecular biological processes could be considered a limitation of the study.

It has been suggested that haploinsufficiency of some genes within the $22 \mathrm{q} 11.2$ region may contribute to the characteristic psychiatric phenotype and cognitive functioning of schizophrenia. ${ }^{29}$ In particular, the Val-108/158-Met COMT polymorphism has received empirical attention as a possible risk factor for psychosis. ${ }^{30}$ The biologic basis of mental illness in $22 q 11 D S$ is not clear yet, but it is clear that the syndrome 
presents an excellent model for understanding psychiatric disorders, especially psychosis, in humans.

The rate of psychosis in 22q11DS is more than 20 times greater than in the general population,,$^{31,32}$ so it is almost possible to affirm that a genomic factor (or genomic factors) in the deleted region exerts some control over brain development or function.

The most commonly reported psychiatric disorders are attention deficit/hyperactivity disorder (ADHD), ${ }^{33,34}$ anxiety ${ }^{20,35,36}$ autism spectrum disorders, ${ }^{37}$ mood disorders including major depression and bipolar disorder, ${ }^{38,39}$ and psychotic disorders. ${ }^{40-42}$ There has also been substantial research focusing on brain structure and function in 22q11DS. ${ }^{43-45}$ Reductions in both grey and white matter volumes have been documented with anomalous characteristics of the corpus callosum, the amygdala, the caudate nucleus, and temporoparietal regions of the brain, and neuroimaging studies on cerebral development in 22q11DS have shown deviant maturational courses characterized by local reductions in brain volume, both gray and white matter density and cortical gyrification and thickness. ${ }^{46-48}$

\section{Genetic outlines}

Since 1981, ${ }^{49}$ an autosomal dominant mode of inheritance for the 22q11DS has been established, and in 1992 Scambler et $\mathrm{al}^{8}$ pointed out that the genetic cause of the syndrome was the interstitial microdeletion of chromosome 22 band 11.2. However, the large majority of cases are by de novo mutation: fewer than $10 \%$ of individuals with 22q11DS inherited the deletion from an affected parent (most frequently mothers with mild neuropsychiatric phenotypes), ${ }^{50}$ and neither parent is affected in over $90 \%$ of cases. ${ }^{51}$ These data indicate that the $22 \mathrm{q} 11.2$ region is quite mutable and susceptible to rearrangement during meiosis, considering also that the penetrance is $100 \%$ with highly variable expression.

This vulnerability of the 11.2 region on chromosome 22 had already been confirmed since the early 1990s by Halford et $\mathrm{al}^{52}$ and Edelmann et al. ${ }^{53,54}$ These studies illustrated that the most common deletions observed within the region of 22q11.2 occur between sets of repeated elements known as low copy repeats (LCRs), which are genomic elements of approximately $200 \mathrm{~kb}$ in length and share high homology with each other; on chromosome 22 at the q11.2 band there are four series of LCRs (A-D) flanking the deletion region. ${ }^{55}$ Because these LCRs share high homology with each other, it appears that during gametogenesis, in the homologous recombination process within the $22 \mathrm{q} 11.2$ region, the LCRs can align inappropriately, leading to a deletion on one recombinant chromosome and a duplication on the other.

Most recombination events occur between LCRs A and D, giving rise to the common $3 \mathrm{Mb}$ deletion. Approximately $8 \%$ of patients have a $1.5 \mathrm{Mb}$ deletion, nested within the $3 \mathrm{Mb}$ deletion. ${ }^{20,54,56}$ It has been argued that the $1.5 \mathrm{Mb}$ deletions contain all key genes responsible for the syndrome and, in particular, for the increased risk of psychiatric illness. ${ }^{5,57}$

The proximal breakpoints region includes the genes located in the $1.5 \mathrm{Mb}$ critical region of 22q11DS that are, among others, encoding frames $P R O D H, C O M T, T B X I$ (T-box1), ZDHHC8 (zinc finger, a member of the DHHC family of palmitoyl transferases [PAT]), DGCR (DiGeorge syndrome critical region protein), and UFDIL (ubiquitin fusion degradation 1-like; with two other proteins it forms a complex involved in both the degradation of ubiquitinated proteins and in mitosis). $A R G D V$ (armadillo repeat gene deleted in velocardiofacial syndrome) is a member of the catenin family that encodes a protein with an N-terminal coiled-coil domain and an armadillo repeat sequence in the midregion, that in a protein complex can facilitate interactions between proteins and a predicted nuclear-targeting sequence, which suggests a nuclear function.

The distal breakpoints include the genes located in the $3 \mathrm{Mb}$ deletion region but outside of the $1.5 \mathrm{Mb}$ critical region. The most investigated are PI4KA (phosphatidylinositol 4-kinase, catalytic, alpha polypeptide), which encodes for a kinase that is involved in the biosynthesis of phosphatidylinositol 4,5-bisphosphate, and SNAP29 (synaptosomal-associated protein [29 kDa]), a member of the SNAP25 gene family that encodes a protein involved in cellular membrane trafficking and is localized in intracellular membrane structures and also in the plasma membrane, but a significant fraction of it is found free in the cytoplasm. ${ }^{58,59}$

As aforementioned, the phenotype of the 22q11DS is highly variable and can affect multiple organs and tissue, but the severity is unrelated to the size of the deletion. However, data suggest that genes within the $1.5 \mathrm{Mb}$ region are crucial for the etiology of the syndrome. It is possible that a small number of genes contribute most of the phenotypic effects, and one or few loci may have a greater phenotypic impact; however, at some level, some form of synergistic interaction between these elements is occurring to substantially increase disease risk. The variability of the cognitive and psychiatric phenotypes of the syndrome may also depend on the presence of additional trans- or cis-acting genetic modifiers. ${ }^{5,28,58}$

Although several genes have been identified as possible susceptibility genes in individuals with 22q11DS and in 
mouse models resembling 22q11DS, there has not been a single candidate gene that has arisen as the only cause of the deletion syndrome. Several candidate genes have attracted attention because of the phenotype that results from their deletion in mouse models. Likewise, studies of human 22q11DS patients have revealed significant genetic variability, and the different array of deletions observed in the patient population does not implicate a single gene as the unique cause. Studies of 22q11DS mouse models have suggested that large numbers of genes in the deleted region are differentially expressed during brain development, and they are candidates for the behavioral phenotype observed in $22 q 11 D S$ individuals. ${ }^{60}$ The evidence from these studies suggest that multiple genes in the deleted region may increase the risk of psychiatric disorders in individuals with 22q11DS and, in the following sections, we will consider four of the most studied candidate genes.

First, we considered the COMT gene, which codes for an enzyme essential in the catabolic clearance of dopamine. COMT is critically involved in cognitive disturbances, and it has often been suggested as a sensitive factor in the development of psychiatric disorders. Next, it will be important to consider the $P R O D H$ gene, encoding for the proline dehydrogenase enzyme, which is involved in the degradation of proline, an agonist of glutamatergic receptors and potentiator of excitatory neurotransmission. The $T B X 1$ gene, will then be discussed; it is a member of the T-box gene family of transcription factors, with an essential role in organogenesis in both vertebrate and invertebrate embryos. Several studies in mice have found TBXI to be the critical cause of the defects found in the 22q11DS phenotype, predominantly the derivatives of the fourth branchial arch artery. Lastly, we considered the ZDHHC8 gene, which encodes for a PAT enzyme. In fact, dysregulation of palmitoylation could contribute to synaptic dysfunction and thus lead to cognitive symptoms in schizophrenia.

\section{COMT}

The COMT gene is located on chromosome $22 \mathrm{q} 11.2$, in the 1.5 $\mathrm{Mb}$ microdeletion region and encodes for a postsynaptic enzyme implicated in dopamine degradation, ${ }^{61}$ especially in the prefrontal cortex (PFC), where wide neuronal expression is found, particularly within layers II, III, and IV of the PFC. ${ }^{5,62,63}$ Here, COMT catalyzes the transfer of a methyl group from $\mathrm{S}$-adenosylmethionine to a hydroxyl group on a catechol nucleus (such as dopamine, norepinephrine, or catechol estrogen). ${ }^{64}$

The level of COMT enzyme activity is genetically polymorphic in human red blood cells and liver.
This polymorphism is due to a guanine to adenine transition at codon 158 of the COMT gene, resulting in a valine--methionine substitution, with a low-activity allele 158-Met and a high-activity allele 158 -Val. These isoforms were shown to influence cortical dopamine levels and cognitive performance in both humans and transgenic mouse models: the COMT functional polymorphism at position 158 leads to a $30 \%$ reduction in enzymatic activity and subsequent accumulation of dopamine within PFC. ${ }^{65,66}$ COMT was considered as a 22q11.2 region candidate gene for psychiatric disorders because of its role in the metabolism of catecholamines.

Despite the many independent studies which confirmed a role for COMT polymorphisms in affecting cognitive performance, other studies have failed to replicate these findings, leaving the influence of the Val158Met COMT polymorphism's impact upon the flexibility of cognition in question. ${ }^{67,68} \mathrm{~A}$ large prospective study by Antshel et $\mathrm{al}^{4}$ found no COMT association with psychotic signs, and similar results were presented by Gothelf et $\mathrm{al}^{69}$ and van Amelsvoort et al. ${ }^{70}$ On the other hand, as for general population samples, performance on frontal lobe-related tasks in 22q11DS may be related to this functional COMT allele. ${ }^{71}$ These discordant results may be due to the complex regulation of dopamine activity in the prefrontal cortex, where activity is impaired in both states of dopaminergic hyperfunction or hypofunction. ${ }^{72}$

COMT polymorphisms seem to be involved in psychotic disorders and in the symptomatology of the schizophreniaspectrum disorders. Several lines of evidence have implicated the COMT gene as a candidate for schizophrenia susceptibility, not only because it encodes a key dopamine catabolic enzyme, but also because it maps to the velocardiofacial syndrome region of chromosome $22 \mathrm{q} 11.2$, which is one of the highest known risk factors for schizophrenia. ${ }^{73}$

\section{PRODH}

The $P R O D H$ gene, found at the far centromeric end of the 22 q11.2 critical region, encodes for the proline dehydrogenase enzyme, which is involved in the degradation of proline, an agonist of glutamatergic receptors and potentiator of excitatory neurotransmission..$^{74,75}$

Patients have either a homozygous deletion or a deletion on one allele with a hypomorphic missense mutation on the other one; about half of all 22q11DS patients show elevated proline levels. ${ }^{76,77}$ Hyperprolinemia is defined by 2-10-fold increased serum levels of proline, and there are two inherited forms of hyperprolinemia, called type 1 and type 2 . Type 1 hyperprolinemia arises from deletion of the 
PRODH gene and presents a highly variable phenotype, in most cases associated with mental retardation and epilepsy. Type 2 hyperprolinemia is caused by mutations in the aldehyde dehydrogenase 4 family, member $A 1$ gene that encodes $\Delta$-1-pyrroline-5-carboxylate dehydrogenase, an enzyme that catalyzes the nicotinamide adenine dinucleotide-dependent oxidation of glutamate semialdehyde to glutamate, which is the final step of proline catabolism. Type 2 hyperprolinemia patients have low intelligence quotient (IQ), seizures, and in some subjects, mild mental retardation. ${ }^{78-80}$

Research on murine PRODH knockouts has shown that these mice have deficits in sensorimotor gating and decreased biosynthesis of glutamate, GABA, and aspartate, and these effects were more pronounced in the frontal cortex. These studies suggested that increased proline levels resulting from decreased proline metabolism can adversely impact tonic neurotransmitter concentrations and may have a bearing on epilepsy, mental retardation, and psychosis, perhaps by adversely modifying neural connections and excitatory neuronal activity. ${ }^{27,81}$ In animal models, Lisman et $\mathrm{al}^{82}$ indicated a relationship between the dysfunctional glutamatergic transmission in the hippocampus and the resulting excess in striatal dopaminergic activity, leading to the glutamate-dopamine theory of psychosis: in those individuals clinically considered at high risk for psychosis this relationship is disrupted, and the severity of disruption is directly correlated with the increased risk of conversion to overt psychosis. ${ }^{5,83}$ Thus, there is an epistatic interaction between the two genes, and the effect of the $P R O D H$ gene is modified by COMT. Also, in utilizing PRODH-deficient mice, it has been hypothesized that a negative-feedback loop restrains increased local hyperdopaminergic tone, which could explain the upregulation of transcript and protein levels of COMT in the PFC. ${ }^{58,84}$

In individuals with $22 \mathrm{q} 11 \mathrm{DS}$, Raux et $\mathrm{al}^{25}$ showed that cognitive performance was inversely correlated with plasma proline levels, and further, hyperprolinemic 22q11DS patients carrying the COMT Met (low-activity) allele had a 2.8-fold increased risk for psychosis. Interestingly, it is believed that decreased inhibition in the hippocampus, perhaps due to N-methyl-D-aspartate receptor hypofunction, may result in increased glutamatergic inputs onto the striatum and an increase in limbic dopaminergic neurotransmission, which can then precipitate psychotic symptoms. ${ }^{83}$

\section{TBXI}

$T B X 1$ is a member of the T-box family of binding domain transcription factors, and it maps within the deleted region of chromosome 22 in $22 q 11 \mathrm{DS}$ (1.5 Mb critical region of 22q11DS). This gene family, characterized by a highly conserved DNA binding motif (T-box) and by an unusual mode of DNA recognition, has essential roles in organogenesis and pattern formation in both vertebrate and invertebrate embryos. ${ }^{85}$

Mice haploinsufficient for $T B X 1$ have phenotypes that recapitulate major features of the syndrome, notably abnormal growth and remodeling of the pharyngeal arch arteries. Knockout mice for this gene have persistent truncus arteriosus, hypoplastic pharynx, lack thymus and parathyroid glands, and have ear, jaw, and vertebral anomalies. ${ }^{86}$ The embryological basis of these abnormalities is the unsuccessful development of the pharyngeal arches and arch arteries 2-6, and of the pharyngeal pouches $2-4$. The severity and extent of the embryological lesion further confirm the importance of $T B X 1$ during the early stages of the development of the entire pharyngeal apparatus, as the segmentation of the pharyngeal endoderm. ${ }^{87,88}$ No other gene so markedly and specifically affects pharyngeal morphogenesis. Moreover, homozygous null mutations of $T B X 1$ have more severe defects including failure of outflow tract septation and absence of the caudal pharyngeal arches.

$T B X 1$ is a transcriptional activator, and loss of this activity has been linked also to alterations in the expression of various genes involved in cardiovascular morphogenesis, confirming that the haploinsufficiency of this gene is largely responsible for the physical malformations in 22q11DS. Cardiovascular malformations in these patients are highly variable, and some studies highlight the potential role of the DNA variations in the $T B X 1$ locus on the remaining allele of 22q11.2. ${ }^{89}$ The identification of eight rare point mutations in the $T B X 1$ gene in families including probands presenting with a 22q11DS-like phenotype, but without any detectable deletion of the $22 \mathrm{q} 11.2$ region, reinforces this hypothesis. ${ }^{86,90}$ However, there is no evidence that $T B X 1$ sequence variants on the intact chromosome 22 are modifiers of the cardiac phenotype in $22 \mathrm{q} 11 \mathrm{DS} .{ }^{91}$ In addition, mouse models of the $22 q 11.2$ deletion show reduced penetrance and variable expression of the cardiac phenotype. Most embryos but only about $30 \%$ of live births show congenital cardiac anomalies, and it is believed that is in part due to compensatory mechanisms and/or redundancy of genes in key pathways during development..$^{92,93}$

Data show that $T B X 1$ haploinsufficiency is responsible for cardiovascular, craniofacial, thymic, and parathyroid defects in mouse models of 22q11.2 microdeletion. ${ }^{94}$

A role for the microvasculature in the pathophysiology of schizophrenia has been proposed on theoretical grounds 
because microvascular damage could satisfy developmental and degenerative models of schizophrenia. ${ }^{95}$ In fact, numerous clinical studies have reported cerebral blood flow abnormalities and increased prevalence of minor physical abnormalities in schizophrenia patients, and also the role of hypoxia and other perinatal problems correlate with increased prevalence of schizophrenia in these individuals.

\section{ZDHHC8}

The ZDHHC8 gene encodes a PAT enzyme, which adds a palmitoyl chemical group to proteins to anchor them to cell membranes. Palmitoylation is a reversible process that involves the covalent attachment of a palmitate group to proteins via thioester bonds at cysteine residues. It plays an important role in regulating nervous system development, dendritic morphology, spine density, synaptic proteins, and glutamatergic neurotransmission. ${ }^{96,97}$ Many neuronal proteins are palmitoylated, and this reversible modification affects their hydrophobicity and so their interaction with cell membranes. This observation underlines the strategic involvement of palmitoylation in neural signaling, and thus as a hemizygous deficiency of $Z D H H C 8$ can significantly affect the development and neural function. ${ }^{98}$

Several studies showed that PAT is localized in the Golgi apparatus and vesicular compartment of neurons where the protein palmitoylation is its central function. ${ }^{99}$ Maynard et $\mathrm{ll}^{100}$ suggested that PAT is localized in the mitochondria, where if normal functions of mitochondrial proteins are disrupted by diminished dosage and altered activity, synaptic changes implicated in the pathogenesis of schizophrenia and other psychiatric disorders may occur. Thus, altered dosage of this 22q11 gene could cause developmental or functional consequences, including altered synaptic development or function that could contribute to increased vulnerability for psychopathology in 22q11DS. ${ }^{98,101,102}$ Furthermore, key proteins implicated in schizophrenia, including glutamic acid decarboxylase 65 (GAD-65) and postsynaptic density protein 95 (also known as PSD-95, that in humans is encoded by DLG4 [discs, large homolog 4]), are known to be regulated dynamically through palmitoylation. ${ }^{97,98,103}$ Also these data confirm the role of palmitoylation: when a dysregulation occurs it could contribute to synaptic dysfunction and cognitive symptoms in schizophrenia.

\section{Psychiatric phenotype of 22q I IDS}

Patients with 22q11DS have cognitive and behavioral impairments and a high risk to develop schizophrenia: the rate of psychosis $22 \mathrm{q} 11 \mathrm{DS}$ is more than 20 times greater than in the general population. ${ }^{31,32}$
Increasing emphasis in the literature focuses on the neurobehavioral phenotype, essentially because psychiatric disorders are amongst the most prevalent manifestations of 22q11DS.,5,35 Like all other components of 22q11DS, the cognitive and behavioral phenotype is highly variable between individuals with the same underlying deletion $22 \mathrm{q} 11.2 .^{20}$

\section{Cognitive impairments and neuropsychiatric disorders}

$22 \mathrm{q} 11 \mathrm{DS}$ is associated with a distinctive cognitive phenotype. ${ }^{104,105}$ The majority of the patients with 22q11DS have an overall intellectual level that falls in the borderline IQ range of 70-84. ${ }^{106,107}$ About one-third have mild intellectual disability, while more severe levels of intellectual disability are uncommon. ${ }^{108,109}$ It is important to note that there is no data about the correlation between a lower intellectual level and increased risk for psychiatric illness, including schizophrenia. ${ }^{110}$ Instead, there are several cross-sectional studies that have found a negative correlation between age and IQ scores in 22q11DS, ${ }^{111-113}$ suggesting in these patients the possibility of a gradual decline in cognitive development as they grow into adulthood. ${ }^{114}$

Reading, spelling, and phonological processing skills as well as rote auditory/verbal memory are relatively spared in 22q11DS. ${ }^{115,116}$ Conversely, math learning disabilities, ${ }^{117,118}$ visuospatial deficits, ${ }^{119}$ attention deficits ${ }^{39,120,121}$ and executive function deficits in domains such as cognitive flexibility, response inhibition, and nonverbal working memory have been reported to be an area of weakness in the 22q11DS cognitive profile. ${ }^{122,123}$

The most commonly reported neuropsychiatric disorders during childhood are attention deficit disorder (present in $30 \%-40 \%$ of individuals with $22 \mathrm{q} 11 \mathrm{DS})^{34}$ and autism spectrum disorders $(10 \%-30 \%),{ }^{39}$ but anxiety disorders, especially simple phobias and separation anxiety, (present in 30\%-40\%) and mood disorders including major depression and bipolar disorder (present in 20\%-30\% $)^{33,39}$ are also common and increase in prevalence during adolescence. ${ }^{124}$ Obsessive compulsive disorder has also been reported. ${ }^{125}$ By adulthood, 20\%-30\% of adults with 22q11DS meet criteria for a diagnosis of schizophrenia, ${ }^{40-42}$ giving an odds ratio for schizophrenia in 22q11DS of around 20:1 relative to the general population. ${ }^{32,39}$

\section{Psychotic disorders and susceptibility to schizophrenia}

Clearly, the most worrying feature of the 22q11DS behavioral profile is the elevated risk for schizophrenia and psychosis that is not associated with any other neurogenetic syndrome. ${ }^{58}$ Identifying shared and unique features for 22q11DS and 
schizophrenia is critical for the understanding of genetic and neural mechanisms underlying both disorders. For these reasons, 22q11DS is considered a human model to study and explore early diagnoses strategies and intervention on schizophrenia-related disturbances.

The 22q11.2 microdeletions account for up to $1 \%-2 \%$ of schizophrenia cases ${ }^{35,39}$ and are the only confirmed recurrent CNV responsible for introducing new cases of schizophrenia into the population. Recent studies, both in humans and animal models, shed light on the growing evidence of a widespread role of this genomic variation in determining susceptibility to schizophrenia. ${ }^{126-129}$

The first observation that supported the importance of rare recurrent mutations in schizophrenia vulnerability dates back to $1995,{ }^{130}$ as a reproducible observation of rare and highly penetrant de novo structural mutations at the 22q11.2 locus in sporadic (nonfamilial) cases of schizophrenia. Rare structural mutations, both inherited and de novo, have a substantial etiological role and account for a considerable portion of sporadic and familial cases of the disease. Interestingly, de novo mutations, such as the 22q11.2 microdeletions, can at least in part explain how schizophrenia persists in the population despite the low fecundity of affected individuals. ${ }^{131,132}$ The 22q11.2 microdeletion is therefore one of the highest known risk factors for schizophrenia, in addition to being the monozygotic twin of a schizophrenic patient and/or sibling or child of an affected individual.

There are no major clinical differences in the core schizophrenia phenotype between individuals with schizophrenia who have the 22q11.2 deletion and those who have not; ${ }^{21,39,133}$ it is important to note that prevalence of schizophrenia in those patients with a learning disability is only about $3 \%$, so there is no correlation between the presence of psychosis and the degree of intellectual impairment, and the mean IQ of individuals with 22q11DS and schizophrenia was in the nonlearning disability range.

In late adolescence and early adulthood, up to one-third of all individuals carrying the 22q11.2 deletion develop schizophrenia or schizoaffective disorder. ${ }^{58,110}$ Twenty to $30 \%$ of adults experience an intensification of psychotic symptoms leading to a diagnosis of schizophrenia, but it is not known whether psychotic symptoms persist at a subthreshold level in the majority of 22q11DS adults who do not develop schizophrenia. It is logical that early psychotic phenomena may predict later psychotic illness including schizophrenia, and there is some evidence for this continuity. ${ }^{39,69,134}$ However, there is no evidence at present that psychotic experiences in 22q11DS are pervasive across diagnoses, contributing to disturbances of mood and anxiety and social interactions. ${ }^{39,69}$
Several studies ${ }^{109,135-137}$ have identified patterns of psychotic, prodromal and associated symptoms in young people with 22q11.2 deletion syndrome. Studies of schoolage children have confirmed that individuals with 22q11DS have high rates of psychiatric and behavior disorders, such as ADHD, generalized anxiety disorder, and obsessive compulsive disorder. ${ }^{108,125,138}$ However, their incidence in 22q11DS is no higher than in other developmental disorders, suggesting that they are not indicative of a behavioral phenotype specifically associated with this syndrome. ${ }^{108}$

A prospective study by Gothelf et $\mathrm{a}^{69}$ found that the development of psychotic symptoms in children studied at age 12 and in follow-up at age 18 was best predicted by the presence of psychotic symptoms at the time of the baseline study and in part by anxiety and depression scores; lower IQ at baseline was also a further predictor. ADHD was not a predictor of psychotic outcomes. ${ }^{34,39}$ By contrast, schizophrenia is specifically associated with 22q11DS. ${ }^{133,137}$ Half of the adolescents with 22q11DS report transient psychotic experiences, while up to one-third of affected adults are diagnosed with schizophrenia. ${ }^{112}$ Moreover, 22q11DS is found in up to one in 50 patients with schizophrenia, with reports ranging from $0.3 \%-2 \% .^{58,130}$ The occurrence of 22q11DS is even higher in patients with childhood-onset schizophrenia (5.7\%). ${ }^{139}$

Moreover, progressive pathology in medial temporal and frontal lobe areas has been associated with emergent psychotic symptomatology in 22q11DS adolescents, ${ }^{140-142}$ and temporal lobe abnormalities are more pronounced in 22q11DS adults with schizophrenia. In particular, Chow et al ${ }^{143}$ linked gray matter volumetric deficits in the superior temporal gyrus to a specific genetic etiology of schizophrenia.

Similarly, in an integrative study of the neuropsychological and brain structural findings in children with 22q11DS, Shashi et $\mathrm{al}^{144}$ have demonstrated reductions in gray matter within the cerebellum, the posterior cortices, the cingulate, and the anterior and middle cingulate gyrus (areas corresponding to the dorsolateral prefrontal cortex); gray matter volumes within the dorsolateral prefrontal cortex, the cingulate, and the cerebellum were positively correlated with performance in the domains of sustained attention, executive function, and verbal memory in addition to intelligence, strengthening the concept that these brain regions are important mediators of neurocognition. These findings enhance our understanding of neurocognition during adolescence and the development of schizophrenia in later life.

It is important to note that Gothelf et al ${ }^{145}$ in a longitudinal study on developmental trajectories of brain structures in 22q11DS adolescents have found a greater longitudinal increase in cranial and cerebellar white matter, 
superior temporal gyrus, caudate nucleus volumes, and a robust decrease in amygdala volume. These findings were associated with a significant decline in verbal IQ scores in those patients that developed psychotic disorders and were linked with more robust reduction of left cortical grey matter volume.

Increased combined prodromal symptoms were associated with longitudinal decreases in the volumes of cranial gray and white matter, prefrontal cortex, mesial temporal lobe, and cerebellum. Interestingly, only decreases in temporal lobe gray matter volumes and verbal IQ predicted specifically to positive prodromal symptoms of psychosis. So, early decrements in temporal lobe gray matter may be predictive of increased risk of prodromal psychotic symptoms in youth with VCFS.

\section{Conclusion}

22 q11.2 deletion is associated with an increased risk of psychiatric disorders, and data show that several susceptibility genes may be located within the deleted region. Future studies will further examine the contribution of genes such as $C O M T, P R O D H$, and $T B X 1$ and the interaction between these and other candidate genes in the deleted region. Even if one or a few genes may have a greater impact, it is the cumulative effect of the imbalance of several genes in the deletion that determines the overall phenotype, and the presence of additional genetic and environmental modifiers may also contribute to the variability of the cognitive and psychiatric phenotypes of the syndrome.

Moreover, an extensive literature on neuroimaging shows reductions of the volumes of both gray and white matter, with abnormalities in corpus callosum, amygdala, caudate nucleus, and the temporoparietal brain region. These findings suggest this reduction may be predictive of increased risk of prodromal psychotic symptoms in 22q11DS patients. The relationship among brain structure, function, connectivity, and cognitive impairments in 22q11DS patients, both children and adults, is an important area of future research and will be essential to compare anomalies in mouse models and humans. This shows that experimental and standardized cognitive assessments alongside neuroimaging may be important to identify one or more endophenotypes of schizophrenia as well as predictive prodrome that can be preventively treated during childhood and adolescence.

Understanding the developmental trajectory of the associated neurobehavioral phenotypes in 22q11DS could also assist with understanding normal human brain development and the molecular genetics underlying this syndrome.

\section{Acknowledgments}

We thank Camilla Fini, Nicoletta Girardi, and Caterina Scicchitano for providing medical writing services and for cooperation during the period of study. We also thank Nicolas Ceglie and Dwight Gijzen for their valuable contributions during the final draft of the article.

The study was fully supported, materially and financially, by Policlinico Umberto I Hospital, Rome, Italy.

\section{Disclosure}

The authors report no conflicts of interest in this work.

\section{References}

1. McDonald-McGinn DM, Sullivan KE. Chromosome 22q11.2 deletion syndrome (DiGeorge syndrome/velocardiofacial syndrome). Medicine (Baltimore). 2011;90(1):1-18.

2. Botto LD, May K, Fernhoff PM, et al. A population-based study of the 22q11.2 deletion: phenotype, incidence, and contribution to major birth defects in the population. Pediatrics. 2003;112(1 Pt 1):101-107.

3. Robin NH, Shprintzen RJ. Defining the clinical spectrum of deletion 22q11.2. J Pediatr. 2005;147(1):90-96.

4. Antshel KM, Shprintzen R, Fremont W, Higgins AM, Faraone SV, Kates WR. Cognitive and psychiatric predictors to psychosis in velocardiofacial syndrome: a 3-year follow-up study. J Am Acad Child Adolesc Psychiatry. 2010;49(4):333-344.

5. Drew LJ, Crabtree GW, Markx S, et al. The 22q11.2 microdeletion: fifteen years of insights into the genetic and neural complexity of psychiatric disorders. Int J Dev Neurosci. 2011;29(3):259-258.

6. Shprintzen RJ, Goldberg RB, Lewin ML, et al. A new syndrome involving cleft palate, cardiac anomalies, typical facies, and learning disabilities: velo-cardio-facial syndrome. Cleft Palate J. 1978;15(1): $56-62$.

7. Goldbert R, Marion R, Borderon M, Wiznia A, Shprintzen RJ. Phenotypic overlap between velo-cardio-facial syndrome and the DiGeorge sequence. Am J Hum Genet. 1985; Suppl 37:A54.

8. Scambler PJ, Kelly D, Lindsay E, et al. Velo-cardio-facial syndrome associated with chromosome 22 deletions encompassing the DiGeorge locus. Lancet. 1992;339(8802):1138-1139.

9. Sedlačková E. The syndrome of the congenital shortening of the soft palate. Cas Lek Ces. 1955;94(12):1304-1307.

10. Sedlačková E. The syndrome of the congenitally shortened velum. The dual innervation of the soft palate. Folia Phoniatr (Basel). 1967;19(6): $441-450$.

11. DiGeorge AM. Congenital absence of the thymus and its immunologic consequences: concurrence with congenital hypoparathyroidism. IV(1). White Plains, NY: March of Dimes-Birth Defects foundation; 1968:116-121.

12. Gayler GG. An "epidemic" of congenital facial paresis and heart disease. Pediatrics. 1967;40(4):666-668.

13. Cayler GG. Cardiofacial syndrome. Congenital heart disease and facial weakness, a hitherto unrecognized association. Arch Dis Child. 1969;44(233):69-75.

14. Wilson DI, Burn J, Scambler P, Goodship J. DiGeorge syndrome: part of CATCH 22. J Med Genet. 1993;30(10):852-856.

15. Burn J. Closing time for CATCH22. J Med Genet. 1999;36(10): 737-738.

16. Bassett AS, Marshall CR, Lionel AC, Chow EW, Scherer. Copy number variations and risk for schizophrenia in 22q11.2 deletion syndrome. Hum Mol Genet. 2008;17(24):4045-4053.

17. Vincent MC, Heitz F, Tricoire J, et al. 22q11 deletion in DGS/ VCFS monozygotic twins with discordant phenotypes. Genet Couns. 1999;10(1):43-49. 
18. Goodship J, Cross I, Scambler P, Burn J. Monozygotic twins with chromosome 22q11 deletion and discordant phenotype. J Med Genet. 1995;32(9):746-748.

19. Maynard TM, Haskell GT, Lieberman JA, LaMantia AS. 22q11 DS: genomic mechanisms and gene function in DiGeorge/velocardiofacial syndrome. Int J Dev Neurosci. 2002;20(3-5):407-419.

20. Philip N, Bassett A. Cognitive, behavioural and psychiatric phenotype in 22q11.2 deletion syndrome. Behav Genet. 2011;41(3): 403-412.

21. Shprintzen RJ, Goldberg R, Golding-Kushner KJ, Marion RW. Lateonset psychosis in the velo-cardio-facial syndrome. Am J Med Genet. 1992;42(1):141-142

22. Michaelovsky E, Gothelf D, Korostishevsky M, et al. Association between a common haplotype in the COMT gene region and psychiatric disorders in individuals with 22q11.2DS. Int J Neuropsychopharmacol. 2008;11(3):351-363.

23. Shifman S, Bronstein M, Sternfeld M, et al. A highly significant association between a COMT haplotype and schizophrenia. Am J Hum Genet. 2002;71(6):1296-1302.

24. Gothelf D, Eliez S, Thompson T, et al. COMT genotype predicts longitudinal cognitive decline and psychosis in 22q11.2 deletion syndrome. Nat Neurosci. 2005;8(11):1500-1502.

25. Raux G, Bumsel E, Hecketsweiler B, et al. Involvement of hyperprolinemia in cognitive and psychiatric features of the $22 \mathrm{q} 11$ deletion syndrome. Hum Mol Genet. 2007;16(1):83-91.

26. Zinkstok J, Schmitz N, van Amelsvoort T, Moeton M, Baas F, Linszen D. Genetic variation in COMT and PRODH is associated with brain anatomy in patients with schizophrenia. Genes Brain Behav. 2008;7(1):61-69.

27. Liu H, Heath SC, Sobin C, et al. Genetic variation at the $22 \mathrm{q} 11$ PRODH2/DGCR6 locus presents an unusual pattern and increases susceptibility to schizophrenia. Proc Natl Acad Sci U S A. 2002;99(6): 3717-3722.

28. van Beveren NJ, Krab LC, Swagemakers S, et al. Functional geneexpression analysis shows involvement of schizophrenia-relevant pathways in patients with $22 \mathrm{q} 11$ deletion syndrome. PLoS One. 2012;7(3):e33473.

29. Schneider M, Van der Linden M, Glaser B, et al. Preliminary structure and predictive value of attenuated negative symptoms in $22 \mathrm{q} 11.2$ deletion syndrome. Psychiatry Res. 2012;196(2-3):277-284.

30. Boot E, Booij J, Abeling N, et al. Dopamine metabolism in adults with 22q11 deletion syndrome, with and without schizophrenia - relationship with COMT Val ${ }^{108 / 58}$ Met polymorphism, gender and symptomatology. J Psychopharmacol. 2011;25(7):888-895

31. Murphy KC, Jones LA, Owen MJ. High rates of schizophrenia in adults with velo-cardio-facial syndrome. Arch Gen Psychiatry. 1999;56(10): 940-945.

32. Ivanov D, Kirov G, Norton N, et al. Chromosome 22q11 deletions, velo-cardio-facial syndrome and early-onset psychosis. Molecular genetic study. Br J Psychiatry. 2003;183:409-413.

33. Antshel KM, Fremont W, Roizen NJ, et al. ADHD, major depressive disorder, and simple phobias are prevalent psychiatric conditions in youth with velocardiofacial syndrome. J Am Acad Child Adolesc Psychiatry. 2006;45(5):596-603.

34. Niklasson L, Rasmussen P, Oskarsdóttir S, Gillberg C. Autism, ADHD, mental retardation and behavior problems in 100 individuals with 22q11 deletion syndrome. Res Dev Disabil. 2009;30(4):763-773.

35. Fung WL, McEvilly R, Fong J, Silversides C, Chow E, Bassett A. Elevated prevalence of generalized anxiety disorder in adults with 22q11.2 deletion syndrome. Am J Psychiatry. 2010;167(8):998.

36. Das Chakraborty R, Chakraborty D, Bernal AJ, et al. Dysregulation of DGCR6 and DGCR6L: psychopathological outcomes in chromosome 22q11.2 deletion syndrome. Transl Psychiatry. 2012;2:e105.

37. Vorstman JA, Morcus ME, Duijff SN. The 22q11.2 deletion in children: high rate of autistic disorders and early onset of psychotic symptoms. J Am Acad Child Adolesc Psychiatry. 2006;45(9): 1104-1113.
38. Papolos DF, Faedda GL, Veit S, et al. Bipolar spectrum disorders in patients diagnosed with velo-cardio-facial syndrome: does a hemizygous deletion of chromosome $22 \mathrm{q} 11$ result in bipolar affective disorder? Am J Psychiatry. 1996;153(12):1541-1547.

39. Baker K, Vorstman JA. Is there a core neuropsychiatric phenotype in 22q11.2 deletion syndrome? Curr Opin Neurol. 2012;25(2):131-137.

40. Murphy KC. Schizophrenia and velo-cardio-facial syndrome. Lancet. 2002;359(9304):426-430.

41. Bassett AS, Chow EW. Schizophrenia and 22q11.2 deletion syndrome. Curr Psychiatry Rep. 2008;10(2):148-157.

42. Bray NJ. Gene expression in the etiology of schizophrenia. Schizophr Bull. 2008;34(3):412-418

43. Eliez S, Blasey CM, Schmitt EJ, White CD, Hu D, Reiss AL. Velocardiofacial syndrome: are structural changes in the temporal and mesial temporal regions related to schizophrenia? Am J Psychiatry. 2001;158(3):447-453.

44. Antshel KM, Conchelos J, Lanzetta G, Fremont W, Kates WR. Behavior and corpus callosum morphology relationships in velocardiofacial syndrome (22q11.2 deletion syndrome). Psychiatry Res. 2005;138(3):235-245.

45. Debbané M, Schaer M, Farhoumand R, Glaser B, Eliez S. Hippocampal volume reduction in 22q11.2 deletion syndrome. Neuropsychologia. 2006;44(12):2360-2365.

46. Kunwar A, Ramanathan S, Nelson J, et al. Cortical gyrification in velo-cardio-facial (22q11.2 deletion) syndrome: a longitudinal study. Schizophr Res. 2012;137(1-3):20-25.

47. Kikinis Z, Asami T, Bouix S, et al. Reduced fractional anisotropy and axial diffusivity in white matter in 22q11.2 deletion syndrome: a pilot study. Schizophr Res. 2012;141(1):35-39.

48. Connor CM, Crawford BC, Akbarian S. White matter neuron alterations in schizophrenia and related disorders. Int J Dev Neurosci. 2011;29(3): 325-334.

49. Shprintzen RJ, Goldberg RB, Young D, Wolford L. The velo-cardiofacial syndrome: a clinical and genetic analysis. Pediatrics. 1981;67(2): 167-172.

50. Costain G, Chow EW, Silversides CK, Bassett AS. Sex differences in reproductive fitness contribute to preferential maternal transmission of 22q11.2 deletions. J Med Genet. 2011;48(12):819-824.

51. Scambler PJ. The 22q11 deletion syndromes. Hum Mol Genet. 2000;9(16):2421-2426.

52. Halford S, Lindsay E, Nayudu M, Carey AH, Baldini A, Scambler PJ. Low-copy-number repeat sequences flank the DiGeorge/velo-cardiofacial syndrome loci at 22q11. Hum Mol Genet. 1993;2(2):191-196.

53. Edelmann L, Pandita RK, Morrow BE. Low-copy repeats mediate the common 3-Mb deletion in patients with velo-cardio-facial syndrome. Am J Hum Genet. 1999;64(4):1076-1086.

54. Edelmann L, Pandita RK, Spiteri E, et al. A common molecular basis for rearrangement disorders on chromosome 22q11. Hum Mol Genet. 1999;8(7):1157-1167.

55. Shaikh TH, Kurahashi H, Saitta SC, et al. Chromosome 22-specific low copy repeats and the 22q11.2 deletion syndrome: genomic organization and deletion endpoint analysis. Hum Mol Genet. 2000;9(4):489-501.

56. Prasad SE, Howley S, Murphy KC. Candidate genes and the behavioral phenotype in 22q11.2 deletion syndrome. Dev Disabil Res Rev. 2008;14(1):26-34.

57. Carlson C, Sirotkin H, Pandita R, et al. Molecular definition of 22q11 deletions in 151 velo-cardio-facial syndrome patients. Am JHum Genet. 1997;61(3):620-629.

58. Karayiorgou M, Simon TJ, Gogos JA. 22q11.2 microdeletions: linking DNA structural variation to brain dysfunction and schizophrenia. Nat Rev Neurosci. 2010;11(6):402-416.

59. Bittel DC, Yu S, Newkirk H, et al. Refining the 22 q11.2 deletion breakpoints in DiGeorge syndrome by aCGH. Cytogenet Genome Res. 2009;124(2):113-120.

60. Sivagnanasundaram S, Fletcher D, Hubank M, Illingworth E, Skuse D, Scambler P. Differential gene expression in the hippocampus of the Df1/+ mice: a model for 22q11.2 deletion syndrome and schizophrenia. Brain Res. 2007;1139:48-59. 
61. Lundström K, Tenhunen J, Tilgmann C, Karhunen T, Panula P, Ulmanen I. Cloning, expression and structure of catechol-O-methyltransferase. Biochim Biophys Acta. 1995;1251(1):1-10.

62. Matsumoto M, Weickert CS, Beltaifa S, et al. Catechol O-methyltransferase (COMT) mRNA expression in the dorsolateral prefrontal cortex of patients with schizophrenia. Neuropsychopharmacology. 2003;28(8):1521-1530.

63. Matsumoto M, Weickert CS, Akil M, et al. Catechol O-methyltransferase mRNA expression in human and rat brain: evidence for a role in cortical neuronal function. Neuroscience. 2003;116(1):127-137.

64. Bearden CE, Jawad AF, Lynch DR, et al. Effects of a functional COMT polymorphism on prefrontal cognitive function in patients with 22q11.2 deletion syndrome. Am J Psychiatry. 2004;161(9):1700-1702.

65. Bonifácio MJ, Vieira-Coelho MA, Soares-da-Silva P. Expression and characterization of rat soluble catechol-O-methyltransferase fusion protein. Protein Expr Purif. 2001;23(1):106-112.

66. Chen J, Lipska BK, Halim N, et al. Functional analysis of genetic variation in catechol-O-methyltransferase (COMT): effects on mRNA, protein, and enzyme activity in postmortem human brain. Am J Hum Genet. 2004;75(5):807-821.

67. Dickinson D, Elvevåg B. Genes, cognition and brain through a COMT lens. Neuroscience. 2009;164(1):72-87.

68. Meyer-Lindenberg A, Weinberger DR. Intermediate phenotypes and genetic mechanisms of psychiatric disorders. Nat Rev Neurosci. 2006;7(10):818-827.

69. Gothelf D, Feinstein C, Thompson T, et al. Risk factors for the emergence of psychotic disorders in adolescents with 22q11.2 deletion syndrome. Am J Psychiatry. 2007;164(4):663-669.

70. van Amelsvoort T, Zinkstok J, Figee M, et al. Effects of a functional COMT polymorphism on brain anatomy and cognitive function in adults with velo-cardio-facial syndrome. Psychol Med. 2008;38(1):89-100.

71. Bassett AS, Caluseriu O, Weksberg R, Young DA, Chow EW. CatecholO-methyl transferase and expression of schizophrenia in 73 adults with 22q11 deletion syndrome. Biol Psychiatry. 2007;61(10):1135-1140.

72. Costas J, Sanjuán J, Ramos-Ríos R, et al. Heterozygosity at catecholO-methyltransferase Val158Met and schizophrenia: new data and meta-analysis. J Psychiatr Res. 2011;45(1):7-14.

73. Gothelf D, Law AJ, Frisch A, et al. Biological effects of COMT haplotypes and psychosis risk in 22q11.2 deletion syndrome. Biol Psychiatry. Epub August 27, 2013.

74. Lang UE, Puls I, Muller DJ, Strutz-Seebohm N, Gallinat J. Molecular mechanisms of schizophrenia. Cell Physiol Biochem. 2007;20(6): 687-702.

75. Cohen SM, Nadler JV. Proline-induced inhibition of glutamate release in hippocampal area CA1. Brain Res. 1997;769(2):333-339.

76. Jacquet H, Demily C, Houy E, et al. Hyperprolinemia is a risk factor for schizoaffective disorder. Mol Psychiatry. 2005;10(5):479-485.

77. Zarchi O, Carmel M, Avni C, et al. Schizophrenia-like neurophysiological abnormalities in 22q11.2 deletion syndrome and their association to COMT and PRODH genotypes. J Psychiatr Res. 2013;47(11):1623-1629.

78. Willis A, Bender HU, Steel G, Valle D. PRODH variants and risk for schizophrenia. Amino Acids. 2008;35(4):673-679.

79. Jacquet H, Raux G, Thibaut F, et al. PRODH mutations and hyperprolinemia in a subset of schizophrenic patients. Hum Mol Genet. 2002;11(19):2243-2249.

80. Clelland CL, Read LL, Baraldi AN, et al. Evidence for association of hyperprolinemia with schizophrenia and a measure of clinical outcome. Schizophr Res. 2011;131(1-3):139-145.

81. Schreiner MJ, Lazaro MT, Jalbrzikowski M, Bearden CE. Converging levels of analysis on a genomic hotspot for psychosis: insights from 22q11.2 deletion syndrome. Neuropharmacology. 2013;68:157-173.

82. Lisman JE, Coyle JT, Green RW, et al. Circuit-based framework for understanding neurotransmitter and risk gene interactions in schizophrenia. Trends Neurosci. 2008;31(5):234-242.

83. Stone JM, Howes OD, Egerton A, et al. Altered relationship between hippocampal glutamate levels and striatal dopamine function in subjects at ultra high risk of psychosis. Biol Psychiatry. 2010;68(7):599-602.
84. Paterlini M, Zakharenko SS, Lai WS, et al. Transcriptional and behavioral interaction between 22q11.2 orthologs modulates schizophrenia-related phenotypes in mice. Nat Neurosci. 2005;8(11):1586-1594.

85. Yagi H, Furutani Y, Hamada H, et al. Role of TBX1 in human del22q11.2 syndrome. Lancet. 2003;362(9393):1366-1373.

86. Lindsay EA. Chromosomal microdeletions: dissecting del22q11 syndrome. Nat Rev Genet. 2001;2(11):858-868.

87. Merscher S, Funke B, Epstein JA, et al. TBX1 is responsible for cardiovascular defects in velo-cardio-facial/DiGeorge syndrome. Cell. 2001;104(4):619-629.

88. Guo T, McDonald-McGinn D, Blonska A, et al; International Chromosome 22q11.2 Consortium. Genotype and cardiovascular phenotype correlations with TBX1 in 1,022 velo-cardio-facial/DiGeorge/22q11.2 deletion syndrome patients. Hum Mutat. 2011;32(11):1278-1289.

89. Scambler PJ. 22q11 deletion syndrome: a role for TBX1 in pharyngeal and cardiovascular development. Pediatr Cardiol. 2010;31(3): 378-390.

90. Paylor R, Lindsay E. Mouse models of 22q11 deletion syndrome. Biol Psychiatry. 2006;59(12):1172-1179.

91. Rauch A, Devriendt K, Koch A, et al. Assessment of association between variants and haplotypes of the remaining TBX1 gene and manifestations of congenital heart defects in 22q11.2 deletion patients. J Med Genet. 2004:41(4):e40.

92. Lindsay EA, Vitelli F, Su H, et al. Tbx1 haploinsufficieny in the DiGeorge syndrome region causes aortic arch defects in mice. Nature. 2001;410(6824):97-101.

93. Lindsay EA, Baldini A. Recovery from arterial growth delay reduces penetrance of cardiovascular defects in mice deleted for the DiGeorge syndrome region. Hum Mol Genet. 2001;10(9):997-1002.

94. Paylor R, Glaser B, Mupo A, et al. Tbx1 haploinsufficiency is linked to behavioral disorders in mice and humans: implications for 22q11 deletion syndrome. Proc Natl Acad Sci U S A. 2006;103(20): 7729-7734.

95. Hanson DR, Gottesman II. Theories of schizophrenia: a geneticinflammatory-vascular synthesis. BMC Med Genet. 2005;6:7.

96. El-Husseini Ael-D, Schnell E, Dakoji S, et al. Synaptic strength regulated by palmitate cycling on PSD-95. Cell. 2002;108(6):849-863.

97. Fukata Y, Fukata M. Protein palmitoylation in neuronal development and synaptic plasticity. Nat Rev Neurosci. 2010;11(3):161-175.

98. Snyder MA, Gao WJ. NMDA hypofunction as a convergence point for progression and symptoms of schizophrenia. Front Cell Neurosci. 2013;7:31.

99. Mukai J, Dhilla A, Drew LJ, et al. Palmitoylation-dependent neurodevelopmental deficits in a mouse model of 22q11 microdeletion. Nat Neurosci. 2008;11(11):1302-1310.

100. Maynard TM, Meechan DW, Dudevoir ML, et al. Mitochondrial localization and function of a subset of 22q11 deletion syndrome candidate genes. Mol Cell Neurosci. 2008;39(3):439-451.

101. Faul T, Gawlik M, Bauer M, et al. ZDHHC8 as a candidate gene for schizophrenia: analysis of a putative functional intronic marker in case-control and family-based association studies. BMC Psychiatry. 2005;5:35

102. Mukai J, Liu H, Burt RA, et al. Evidence that the gene encoding ZDHHC8 contributes to the risk of schizophrenia. Nat Genet. 2004;36(7):725-731.

103. Kanaani J, Patterson G, Schaufele F, Lippincott-Schwartz J, Baekkeskov S. A palmitoylation cycle dynamically regulates partitioning of the GABA-synthesizing enzyme GAD65 between ER-Golgi and post-Golgi membranes. J Cell Sci. 2008;121(Pt 4):437-449.

104. Furniss F, Biswas AB, Gumber R, Singh N. Cognitive phenotype of velocardiofacial syndrome: a review. Res Dev Disabil. 2011;32(6): 2206-2213.

105. Shprintzen RJ. Velo-cardio-facial syndrome: a distinctive behavioral phenotype. Ment Retard Dev Disabil Res Rev. 2000;6(2):142-147.

106. Chow EW, Watson M, Young DA, Bassett AS. Neurocognitive profile in 22q11 deletion syndrome and schizophrenia. Schizophr Res. 2006;87(1-3):270-278. 
107. Swillen A, Devriendt K, Legius E, et al. The behavioural phenotype in velo-cardio-facial syndrome (VCFS): from infancy to adolescence. Genet Couns. 1999;10(1):79-88.

108. Bassett AS, Chow EW, Husted J, et al. Clinical features of 78 adults with 22q11 Deletion Syndrome. Am J Med Genet A. 2005;138(4):307-313.

109. Swillen A, Vogels A, Devriendt K, Fryns JP. Chromosome 22q11 deletion syndrome: update and review of the clinical features, cognitive-behavioral spectrum, and psychiatric complications. Am J Med Genet. 2000;97(2):128-135.

110. Feinstein C, Eliez S, Blasey C, Reiss AL. Psychiatric disorders and behavioral problems in children with velocardiofacial syndrome: usefulness as phenotypic indicators of schizophrenia risk. Biol Psychiatry. 2002;51(4):312-318.

111. Gothelf D, Aviram-Goldring A, Burg M, et al. Cognition, psychosocial adjustment and coping in familial cases of velocardiofacial syndrome. J Neural Transm. 2007;114(11):1495-1501.

112. Green T, Gothelf D, Glaser B, et al. Psychiatric disorders and intellectual functioning throughout development in velocardiofacial (22q11.2 deletion) syndrome. J Am Acad Child Adolesc Psychiatry 2009;48(11):1060-1068.

113. Niklasson L, Gillberg C. The neuropsychology of 22q11 deletion syndrome. A neuropsychiatric study of 100 individuals. Res Dev Disabil. 2010;31(1):185-194.

114. Duijff SN, Klaassen PW, de Veye HF, Beemer FA, Sinnema G, Vorstman JA. Cognitive development in children with 22q11.2 deletion syndrome. Br J Psychiatry. 2012;200(6):462-468.

115. Majerus S, Glaser B, Van der Linden M, Eliez S. A multiple case study of verbal short-term memory in velo-cardio-facial syndrome. J Intellect Disabil Res. 2006;50(Pt 6):457-469.

116. Lajiness-O'Neill RR, Beaulieu I, Titus JB, et al. Memory and learning in children with 22q11.2 deletion syndrome: evidence for ventral and dorsal stream disruption? Child Neuropsychol. 2005;11(1):55-71.

117. Vicario CM, Yates MJ, Nicholls ME. Shared deficits in space, time, and quantity processing in childhood genetic disorders. Front Psychol. 2013;4:43.

118. De Smedt B, Swillen A, Devriendt K, Fryns JP, Verschaffel L, Ghesquiere P. Mathematical disabilities in young primary school children with velo-cardio-facial syndrome. Genet Couns. 2006;17(3):259-280.

119. Bearden CE, Woodin MF, Wang PP, et al. The neurocognitive phenotype of the 22q11.2 deletion syndrome: selective deficit in visualspatial memory. J Clin Exp Neuropsychol. 2001;23(4):447-464.

120. Antshel KM, Hendricks K, Shprintzen R, et al. The longitudinal course of attention deficit/hyperactivity disorder in velo-cardio-facial syndrome. J Pediatr. 2013;163(1):187-193. e1.

121. Shapiro HM, Takarae Y, Harvey DJ, Cabaral MH, Simon TJ. A crosssectional study of the development of volitional control of spatial attention in children with chromosome 22q11.2 deletion syndrome. $J$ Neurodev Disord. 2012;4(1):5.

122. Van Aken K, Swillen A, Beirinckx M, Janssens L, Caeyenberghs K, Smits-Engelsman B. Prospective control abilities during visuo-manual tracking in children with 22q11.2 Deletion syndrome compared to ageand IQ-matched controls. Res Dev Disabil. 2010;31(3):634-641.

123. Sobin C, Kiley-Brabeck K, Karayiorgou M. Associations between prepulse inhibition and executive visual attention in children with the 22q11 deletion syndrome. Mol Psychiatry. 2005;10(6):553-562.

124. Jolin EM, Weller RA, Weller EB. Occurrence of affective disorders compared to other psychiatric disorders in children and adolescents with 22q11.2 deletion syndrome. J Affect Disord. 2012;136(3):222-228.

125. Gothelf D, Presburger G, Zohar AH, et al. Obsessive-compulsive disorder in patients with velocardiofacial (22q11 deletion) syndrome. Am J Med Genet B Neuropsychiatr Genet. 2004;126B(1):99-105.

126. Kirov G, Pocklington AJ, Holmans P, et al. De novo CNV analysis implicates specific abnormalities of postsynaptic signalling complexes in the pathogenesis of schizophrenia. Mol Psychiatry. 2012;17(2): $142-153$.
127. Magri C, Sacchetti E, Traversa M, et al. New copy number variations in schizophrenia. PLoS One. 2010;5(10):e13422.

128. Stefansson H, Rujescu D, Cichon S, et al; GROUP. Large recurrent microdeletions associated with schizophrenia. Nature. 2008;455(7210): 232-236.

129. Jonas RK, Montojo CA, Bearden CE. The 22q11.2 deletion syndrome as a window into complex neuropsychiatric disorders over the lifespan. Biol Psychiatry. Epub August 27, 2013.

130. Karayiorgou M, Morris MA, Morrow B, et al. Schizophrenia susceptibility associated with interstitial deletions of chromosome $22 \mathrm{q} 11$. Proc Natl Acad Sci U S A. 1995;92(17):7612-7616.

131. Xu B, Roos JL, Levy S, van Rensburg EJ, Gogos JA, Karayiorgou M. Strong association of de novo copy number mutations with sporadic schizophrenia. Nat Genet. 2008;40(7):880-885.

132. Cook EH, Scherer SW. Copy-number variations associated with neuropsychiatric conditions. Nature. 2008;455(7215): 919-923.

133. Bassett AS, Chow EW, AbdelMalik P, Gheorghiu M, Husted J, Weksberg R. The schizophrenia phenotype in $22 \mathrm{q} 11$ deletion syndrome. Am J Psychiatry. 2003;160(9):1580-1586.

134. Debbané M, Glaser B, David MK, Feinstein C, Eliez S. Psychotic symptoms in children and adolescents with 22q11.2 deletion syndrome: neuropsychological and behavioral implications. Schizophr Res. 2006;84(2-3):187-193.

135. Gothelf D, Schaer M, Eliez S. Genes, brain development and psychiatric phenotypes in velo-cardio-facial syndrome. Dev Disabil Res Rev. 2008;14(1):59-68.

136. Baker K, Baldeweg T, Sivagnanasundaram S, Scambler P, Skuse D. COMT Val108/158 Met modifies mismatch negativity and cognitive function in 22q11 deletion syndrome. Biol Psychiatry. 2005;58(1): 23-31.

137. Arnold PD, Siegel-Bartelt J, Cytrynbaum C, Teshima I, Schachar R Velo-cardio-facial syndrome: implications of microdeletion 22q11 for schizophrenia and mood disorders. Am JMed Genet. 2001;105(4): 354-362.

138. Ousley O, Rockers K, Dell ML, et al. A review of neurocognitive and behavioral profiles associated with $22 \mathrm{q} 11$ deletion syndrome: implications for clinical evaluation and treatment. Curr Psychiatry Rep. 2007;9(2):148-58

139. Sporn A, Addington A, Reiss AL, et al. 22q11 deletion syndrome in childhood onset schizophrenia: an update. Mol Psychiatry. 2004;9(3): 225-226.

140. Gothelf D, Hoeft F, Ueno T, et al. Developmental changes in multivariate neuroanatomical patterns that predict risk for psychosis in 22q11.2 deletion syndrome. J Psychiatr Res. 2011;45(3): $322-331$.

141. Kates WR, Antshel KM, Faraone SV, et al. Neuroanatomic predictors to prodromal psychosis in velocardiofacial syndrome (22q11.2 deletion syndrome): a longitudinal study. Biol Psychiatry. 2011;69(10): 945-952.

142. Kates WR, Bansal R, Fremont W, et al. Mapping cortical morphology in youth with velocardiofacial (22q11.2 deletion) syndrome. $\mathrm{J} \mathrm{Am}$ Acad Child Adolesc Psychiatry. 2011;50(3):272-282. e2.

143. Chow EW, Ho A, Wei C, Voormolen EH, Crawley AP, Bassett AS Association of schizophrenia in 22q11.2 deletion syndrome and gray matter volumetric deficits in the superior temporal gyrus. Am J Psychiatry. 2011;168(5):522-529.

144. Shashi V, Francis A, Hooper SR, et al. Increased corpus callosum volume in children with chromosome $22 \mathrm{q} 11.2$ deletion syndrome is associated with neurocognitive deficits and genetic polymorphisms. Eur J Hum Genet. 2012;20(10):1051-1057.

145. Gothelf D, Penniman L, Gu E, Eliez S, Reiss AL. Developmental trajectories of brain structure in adolescents with 22q11.2 deletion syndrome: a longitudinal study. Schizophr Res. 2007;96(1-3): 72-81. 


\section{Publish your work in this journal}

Neuropsychiatric Disease and Treatment is an international, peerreviewed journal of clinical therapeutics and pharmacology focusing on concise rapid reporting of clinical or pre-clinical studies on a range of neuropsychiatric and neurological disorders. This journal is indexed on PubMed Central, the 'PsycINFO' database and CAS.

The manuscript management system is completely online and includes a very quick and fair peer-review system, which is all easy to use. Visit http://www.dovepress.com/testimonials.php to read real quotes from published authors.

\footnotetext{
Submit your manuscript here: http://www.dovepress.com/neuropsychiatric-disease-and-treatment-journal
} 